\title{
Recent Experience with the Computer Science Accreditation Process
}

\author{
Chao Lu, Doris K. Lidtke, Charles Dierbach, and Gabriele Meiselwitz \\ Department of Computer and Information Sciences, Towson University, Towson, Maryland 21252 \\ USA \\ cdierbach@towson.edu
}

Keywords: accreditation, assessment, competencies, curriculum policies

\begin{abstract}
Accreditation of programs in Computer Science in the USA began in 1986. There are now over 150 accredited programs and the number is increasing each year (CSAB 1997). There is significant international interest in the mutual recognition and coordination of accreditation of computer science academic programs. The B.S. of Computer Science program at the Department of Computer \& Information Sciences, Towson University received the Computing Sciences Accreditation Board (CSAB) initial accreditation in 1994, and has just gone through a reaccreditation visit during the Fall 1999. In this paper, we would share our experiences of the computer science accreditation process; lessons leamed, and present our curriculum as one example of the accredited computer science programs in USA.
\end{abstract}

\section{BACKGROUND AND DEFINITION}

Accreditation of programs in Computer Science in the USA began in 1986. There are now over 150 accredited programs and the number is increasing each year (CSAB 1997). An accredited program is one that has been reviewed by qualified, trained visitors and meets the Criteria established Computer Science Accreditation Commission (CSAC) and approved by the CSAB. Only programs that are in institutions that have regional accreditation can be considered. This means that the evaluators visiting the institution are assured that the institution has in place the 
necessary infrastructure to offer programs leading to the degrees they offer, particularly on the undergraduate (baccalaureate) level. The accreditation process is nearly two years long and involves a self study by the program requesting accreditation, a visit by three qualified evaluators, formal analysis of the program, and finally a vote by the CSAC at their annual meeting. Accreditation of a program is for 6 or 3 years. A three year accreditation is for programs which are deemed to have some issues regarding stability of the program, for example, many recent, substantive changes in the institution, many significant changes in the curriculum that may not be fully implemented, or a history of difficulty with keeping faculty.

\section{THE PROCESS}

The first important step in considering accreditation is to see if the program meets the CSAC/CSAB Criteria. If a program needs help or guidance, the department may hire a consultant, who is experienced with CSAC accreditation, or may send an observer to a CSAB session on training for Program Evaluators, where the observer will learn more about the process, particularly how Criteria are interpreted and applied.

Once the department feels that their program will probably meet the Criteria, they begin to prepare the self-study and to collect course materials, about a year prior to the visit. This is a good time to discuss the process with the administration of the institution to be certain that they are supportive of the process and willing to provide the money for the fees. By January 31 of the year the program is to be visited, the institution needs to submit a Request for Evaluation form. By June 1 of the same year the institution must pay the fee for the accreditation visit. In late Spring the institution will be sent a list of Program Evaluators (PEs) and Team Chairpersons (TCs). The institution is asked to cross off any PEs or TCs that they choose not to have as visitors. Those excluded should include recent former faculty, consultants, graduates, and anyone who may have a conflict of interest concerning the program.

The self-study must be submitted to CSAC by July 1 of the year of the visit. This two volume document is key to the accreditation process. In preparing this self-study the faculty of the program must critically analyse their program in all its aspects. The self-study by the program includes detailed documentation of the curriculum, the students, the faculty and the environment in which the program is delivered. The forms for the self-study are available on the web at www.csab. Detail required includes all courses in computer science that count toward the major. syllabi for all courses and 
details about the material covered in each course, faculty vitas, and information about students in the program.

In July, using the list of visitors acceptable to the institution and eliminating all PEs and TCs who live in the same or an adjacent state, CSAC will pick a TC for each institution to be visited in the fall. The TC will be given the names of at least two possible PEs to try to form a team. Once the TC has formed a team, they will contact the institutional contact person and agree the exact dates and schedule for the visit.

During the two-day, on campus visit, the team will talk with students, faculty and the leading administrators. The team will also examine course displays, which include the syllabus, a copy of the textbook, all handouts supplied to the students, and samples of graded student work from homework, tests, projects and examinations. These samples must include both work of excellent students, but also work representative of average and poor students. The three people who visit the institution to evaluate the program comprise a team. There are two Program Evaluators (PEs) and a Team Chair (TC). The program evaluators are nominated by the societies, which established CSAB, the Association of Computing Machinery (ACM) and the IEEE Computer Society (IEEE-CS). The TC will have served on several previous visits as a PE. Each TC is asked to evaluate the PEs on the team and based upon their evaluation and the evaluation by the institution itself. Several Program Evaluators are invited each year to become Team Chairs in the coming year. There is an effort made to have at least one industry representative on each team.

\section{CRITERIA FOR PROGRAM EVALUATION}

A program should be designed to provide a broad general education at the baccalaureate level so that they can function effectively in the profession. 'Programs designed to prepare graduates for supporting roles, for example technician, are not eligible, nor are programs that fail to provide an adequate base for the application of concepts fundamental to the discipline (CSAB 1997)' Although special circumstances, such as evening or cooperative baccalaureate programs and distance education, are not specifically addressed, these programs are eligible for consideration. 'The criteria are intended to assure an adequate foundation in science, mathematics, the humanities and social sciences, and computer science fundamentals, and to assure appropriate preparation in advanced computer science. They are designed to be flexible enough to permit the expression of an institution's individual qualities and ideals. [They] are intended to encourage and stimulate creative and imaginative programs (CSAB 1997)'. Nothing should 
be interpreted as constraining an institution in the development of its educational programs.

The criteria are divided into five major categories: Faculty, Curriculum, Laboratory and Computing Resources, Students and Institutional Support. The self-study and the team visit examine each of the criteria in detail. The original Criteria which was used for the first CSAC visits was modelled after the ABET Criteria for accrediting programs in engineering. The only category, which differed to any large extent, was the section on curriculum. Over the years the self-study documents have evolved in each organisation and are somewhat different.

\section{WHO BENEFITS FROM ACCREDITATION?}

Many groups benefit from accreditation, including students, employers, the public, and the institution, department and the program. The students benefit by being assured that they are being taught what they need to know to prepare them to function as a professional in the computer science field. They are able to choose to go to a university which has shown that it provides the type of education which is deemed necessary by CSAB and the professional societies which support CSAB, ACM and IEEE-CS. The students' parents have the assurance that they are paying for an education which will adequately prepare their son or daughter to enter the workforce or go on to graduate studies in the field.

Employers value accreditation because it insures a minimum level of preparation for the students they hire. Accreditation provides the employer with a workforce which has acquired a certain level of ability in the field. Employers are encouraged to have their personnel participate in the accreditation process, specifically by commenting on changes in the Criteria and serving as Program Evaluators and Team Chairs. As business, industry, government and individuals rely increasingly on computers and software, it is vital that minimum standards of preparation of workers be set in place. Accreditation is one way to assure minimum preparation of people entering the field. As more computer systems can impact the life, health and safety of people, it is important that computer professionals be adequately prepared for their work.

The institution, the department and the program that is accredited also benefit. The reputation of the institution is enhanced when the program is recognised as having met the standards of accreditation. The department benefits by having a recognised program as they recruit students and try to attract and retain faculty. The program benefits by being constantly reviewed and improved. 


\section{PREPARATION FOR ACCREDITATION}

Preparation for accreditation requires considerable effort; a program may need to spend several years studying the Criteria and seeing how close their program is to meeting each criterion. For accredited programs, the reaccreditation process requires a minimum of 20 months, though two years is generally recommended. The formal process begins with the submission of a Request for Evaluation by January of the year prior to the visit by the evaluators. For the process to go smoothly, the program should be continuously reviewed, updated and care taken to be sure that all of the criteria continue to be followed. The collection of current syllabi, handouts and graded student work needs to be done a year prior to the visit.. Every member of the program should be involved in the process. Motivating all faculty members and students to participate and getting all course materials collected are not trivial tasks, especially if the program has a large number of majors. First, an internal team consisting of two or three experienced faculty and the department chair is formed. Each member of the internal accreditation team should be assigned specific tasks with deadlines. Assigned time should be given to these members for their work. The team should meet regularly to update each other on progress and to discuss and address any problems.

The self-study, Questionnaire for Review of the Computer Science Program, needs to be prepared and sent to CSAB by July prior to the visit. Both academic and administrative issues are addressed. The program will be initially evaluated on the basis of the data provided in the self-study. Programs without an adequate self-study within the time will not be considered. Collecting data and preparation is the most important first step of initial accreditation, as well as for re-accreditation.

The Administration should be informed of each step in the process and receive a copy of the self-study when completed. Since the University senior managemenet will be involved, co-ordination with their offices is necessary. Scheduling is crucial since the accreditation visit involves so many university administrators, all the faculty members in the department, some faculty members from other related departments, staff members from library and other units in the university.

The accreditation visit is usually scheduled in the Fall. Prior to the visit, all the course material and textbooks should be set up for display in a conference room. All faculty and staff should be available during the on-site visit; on the first day the team chair interviews all the administrators then other related staff while the other two team members interview all the faculty members and students. On the second day the team meets to discuss the visit among themselves, then the team debriefs the Chair, then the 
President. These exit meetings with the team are an opportunity to correct any errors in fact that the team may have, and to provide missing information. Also in the exit interviews the team will point out any deficiencies in the program and any concerns they have. Any program that has a deficiency by the time of the Annual Meeting of CSAC will not be accredited. So if the team points out a deficiency, the faculty should begin work immediately to change things so that the deficiency no longer exists. Concerns should also be addressed.

During the ten days following the visit the institution and program may submit any evidence to the team to show that a deficiency has been remedied. Information submitted within the ten days accepted. In Spring the institution will receive a Preliminary Statement from CSAC detailing the findings of the visiting team and listing explicitly any deficiencies and concerns. The institution has 30 days to reply to this statement. This is time to provide proof that deficiencies have been eliminated and concerns addressed. Then before the annual meeting of CSAC, the institution may still submit any supplemental information to the Commission for consideration of the evaluation team's report.

Program accreditation assists in quality assurance and enhances opportunities for international interchange. Towson University has a large computer science graduate program with many international students. It would be helpful to identify students coming from accredited institutions at admission at both the graduate and undergraduate levels.

\section{CHANGES IN CRITERIA}

In 2000 the Criteria for Accrediting Programs in the United States (CSAB 2000) was revised. This new Criteria has the same goals as the previous criteria; most programs meeting the previous criteria would meet the new. One area that is markedly different is on Objectives and Assessments. Here the intent is that 'The program has documented objectives, including expected outcomes for graduates. The program regularly assesses its progress against its objectives and uses the results of the assessments to identify program improvements and to modify the program's objectives.' Thus the goal of accreditation is quality assurance. 


\section{INTERNATIONAL ACTIVITIES AND IMPLICATIONS}

For a number of years $\mathrm{CSAC} / \mathrm{CSAB}$ has been interested in developing mutual recognition of accredited programs with other countries, granting substantial equivalence to programs outside the USA, and assisting in the development of their own accreditation process. Dr. Willis King, University of Houston, Texas, has been a leader in this activity (IWCSEA 1996). He was convener of the National Science Foundation supported International Workshop on Computer Science and Engineering Accreditation in Salt Lake City, Utah, in 1996. He is also the Principal Investigator for a joint project between the USA and the European Union to investigate the possibility of mutual recognition of programs in computer science. This project attempts to promote student exchange, 'to exchange ideas and experiences in curriculum development, and to stimulate collaboration and harmonisation of degree programs in computer science. ... The ultimate goal of the project is to promote mutual recognition of academic degrees in computer science. In these days, when more and more governments are advocating the licensing of practitioners of computing sciences, it will be beneficial to our graduates if their degrees are recognised internationally.' (Willis 1999) The three courses which were developed as a part of this project were presented at the Frontiers in Education (FIE'99) in November 1999 in San Juan, Puerto Rico. (Clements 1999, Lidtke 1999, Oswald 1999).

\section{AN EXAMPLE CURRICULUM}

We present here our current curriculum as an example of accredited programs (TU 1999).

A.Title of degree - Major: Computer Science. Diploma Bachelor of Science

B. Credit Hour Definition: One semester hour normally represents one class hour or three laboratory hours per week. One academic year normally represents at least 28 weeks of classes exclusive of final examinations. But the COSC 236, Introduction to Computer Science I, has a two-hour lab that counts as one hour of course credit. Three additional hours of lecture account for the total of four credit hours. Students have two hours of closed lab, and must spend additional time in open lab. Numbers represent credit hours

Computer Science Curriculum

Core courses:

COSC 236 Introduction to Computer Science I (4)

COSC 237 Introduction to Computer Science II (4)

COSC 280 Assembly Language/ Computer Architecture (3)

COSC 336 Data and File Structures (4) 
COSC 338 Computer Organisation and Architecture (4)

MATH 263 Discrete Mathematics (3)

MATH 273 Calculus I (4)

MATH 274 Calculus II (4)

MATH 330 Introduction to Statistical Methods

Lab Science I (Lab science - 1st of sequence) (4)

Lab Science II (Lab science - 2nd of sequence) (4)

Science Elective (Science required by respective major)

Science Elective (Science required by respective major)

Total credits: $46-48$

Advanced courses:

COSC 439 Operating Systems (3)

COSC 455 Programming Languages: Design + Implementation (3)

COSC 457 Database Management Systems (3)

COSC xxx Category A Elective (3)

COSC xxx Category A Elective (3)

COSC xxx Category B Elective (3)

COSC xxx Category B Elective (3)

MATH xxx Upper Level Math Elective (3-4)

COSC 480 Senior Seminar (1)

Total credits: $27-28$

Computer Science Elective Categories:

Category A: Theory-Related Electives

COSC 367 - Discrete Structures (3)

COSC 415 - Compiler Design (3)

COSC 417 - Theory of Computing (3)

COSC 441 - Performance Evaluation (3)

COSC 459 - Simulation and Modelling (3)

COSC 461 - Artificial Intelligence (3)

COSC 483 - Design and Analysis of Algorithms (3)

Category B: - Application Related Electives

COSC 350 - Data Communications and Networking (3)

COSC 412 - Software Engineering (3)

COSC 431 - Selected Topics (3)

COSC 438 - Parallel/Vector Computing (3)

COSC 471 - Computer Graphics (3)

D. Overall Accreditation Curriculum Requirements

The minimum curriculum requirements established by CSAB for program accreditation:

Total amount of computer science. The program must have at least one and one-third years of computer science topics (at least 40 semester hours).

Core courses. The computer science segment of the curriculum must have a broad-based core consisting of the equivalent of 16 semester hours. (Basic coverage of algorithms, data 
structures, software design, concepts of programming languages, and computer organisation and architecture).

Theoretical foundations. At least the equivalent of three semester hours of theoretical material in the required core courses.

Mathematics requirement. The curriculum must include at least one-half year (at least 15 semester hours) of mathematics.

Science requirement. The curriculum must include at least two-fifths (the equivalent of 12 semester hours) of a year of science, accepted in that major. In addition, two courses must form a sequence.

Overall mathematics/Science requirement.

CSAB criteria require that the combined total of all required mathematics and science courses be at least one year of study (equivalent to 30 semester hours).

General education courses. CSAB criteria require that there be at least one full year of courses from the following areas: Humanities, social sciences, arts, and other disciplines that serve to broaden the background of the student.

Other. It is also required that students be trained in two other areas: Oral and communication skills, and ethical and societal implications of computing.

Programs are expected to meet the above minimum requirements in order to receive accreditation.

\section{CONCLUSIONS}

The curriculum presented here integrates technical requirements with general education requirements and electives to prepare students for a professional career in the computer science field. While some of our graduates go on to graduate education, a large majority of our graduates go to work in industry and government agencies. Our program stresses two important components: a broad-based theoretical foundation, and the latest development of computer technology. The core provides basic coverage of algorithms, data structures, software design, concepts of program languages, and computer organisation and architectures. Closed laboratories (i.e., laboratory time with instructor) are used in Computer Science I (COSC236) and Computer Organisation (COSC338). Electives provide area-specific topics of computer science, with COS431 Special Topics in Computer Science dealing with topics of the latest technology. Given the fast changes in the computing field, the curriculum needs to be continuously reviewed and updated while making sure that all the regulations of accreditation are followed.

Program accreditation not only assists in quality assurance, but also greatly enhances opportunities for international interchange. Towson University has a large computer science graduate program with many 
international students, and therefore identifying students coming from accredited institutions during the admission process would be of great benefit.

\section{REFERENCES}

Clements, A. (1999) Towards A Modern Computer Architecture Curriculum. In Proceedings of Frontiers in Education Conference, A. Clements, A. Shvartsman, W. King, C. Lu, and D. Dupont (eds.), (FIE '99, November 10-14 1999), San Juan, Puerto Rico, pp. 11b8-4-9.

CSAB (Computer Science Accreditation Commission ) (1997) Evaluative Criteria. 1997 Annual Report, 34-35, Computing Sciences Accreditation Board, Inc.

CSAB (Computer Science Accreditation Commission) (2000) Criteria for Accrediting Programs in Computer Science in the United States. January 2000, version 1.0. [www.csab.org/criteria2k_v10.html].

IWCSEA (1996) International Workshop on Computer Science and Engineering Accreditation. Salt Lake City, Utah, USA, Nov. 10-11, 1996.

Lidtke, D. (1999) Professionalism and Social Issues in Informatics: An International, collaborative Curriculum Development Project. In Proceedings of Frontiers in Education Conference, D. K. Lidtke, M. Israel, G. L. Engel, E. L. Leiss, and D. Waetjen (eds.), (FIE '99, November 10-14, 1999), San Juan, Puerto Rico, pp. 11b8-10-13.

Oswald, A. (1999) An International Common Project Model. In Proceedings of Frontiers in Education Conference, A. Oswald, S. Azadegan, M. Aiguier, D. Smarkusky, S. Huang and J. Spiess (eds.) (FIE '99, November 10-14, 1999), San Juan, Puerto Rico, pp. 11b8-14-17.

TU (Towson University) (1999) Questionnaire for Review of the Computer Science Program to the Computer Science Accreditation Commission for the 1999-2000 accreditation cycle. Volume II, Department of Computer and Information Sciences, Towson University.

Willis, K. et al. (1999) Towards a common computer science curriculum and mutual degree recognition - An Intercontinental Project. In Proceedings of Frontiers in Education Conference, W. K. King and M. Israel (FIE '99, November 10-14, 1999), San Juan, Puerto Rico, pp. 11b8-1-3.

\section{BIOGRAPHY}

Chao $\mathrm{Lu}$ is chair of the department, Doris Lidtke is professor in the department and active in computer science curriculum development both nationally and internationally, Charles Dierbach is Associate Professor and has been involved in introductory computer science course development, and Gabriele Meiselwitz is active in course science course development for nonmajors. 